\title{
ISOMETRIC AND ISOKINETIC BACK AND ARM LIFTING STRENGTHS: DEVICE AND MEASUREMENT
}

\author{
S. KUMAR \\ Department of Physical Therapy, 216A Corbett Hall, The University of Alberta, Edmonton, \\ Canada, T6G 2G4 \\ and \\ DON B. ChafFIN and MARK REDFERN \\ Center for Ergonomics, The University of Michigan, Ann Arbor, MI, U.S.A.
}

\begin{abstract}
This study was conducted to measure isometric (static) and isokinetic (dynamic) back and arm lifting strengths at 20,60 and $100 \mathrm{~cm} \mathrm{~s}^{-1}$ of young adults. Ten male and ten female volunteers without a history of back pain participated. The isokinetic lifting task was achieved by designing and fabricating a servo controlled motorized dynamic strength tester (DST). A regression analysis and analysis of variance was carried out on the strength data. The peak static strength values were significantly greater from the peak dynamic strength values. The peak dynamic strength was inversely related to the speed of motion. There were significant differences between the dynamic strengths at different stages of lift.
\end{abstract}

\section{INTRODUCTION}

Holbrook et al. (1984) estimated cost of low back pain in the United States to be of the order of $\$ 15.87$ billion dollars annually. In Alberta the new claims registered for back problems for the years 1983 and 1984 were 45.4 and $42.7 \%$ respectively (WCB Alberta 1985). Based on the assumption of proportional cost regardless of the body part, back problems can be estimated to have cost (total operating transaction cost from the Workers Compensation Board of Alberta) 113.7 and 99.7 million dollars for the years 1983 and 1984 respectively.

In order to control low back pain various preventive strategies have been proposed. Since industrial lowback pain, regardless of its aetiology, is a biomechanical phenomenon, strength performance capability is an appropriate criterion to use in a control strategy. Chaffin, Herrin and Keyserling (1978) demonstrated that the incidence rate of back injuries sustained at the job increased when the job strength requirements. exceeded the isometric strength of the workers. Keyserling, Herrin and Chaffin (1980) found that the incidence rate among employees who were selected using isometric strength tests was approximately onethird that of employees selected using traditional medical criteria. As a result of these types of studies isometric strength measures have been often used in industry, even though most tasks are dynamic in nature. Moving with a load may affect the maximal strength performance characteristics of workers Bearing this in mind Kroemer (1983) proposed an isoinertial method of determining maximal lifting capability for individuals. This technique required the

Received August 1986; in revised form February 1987. repeated testing of subjects with increasing weights until the maximum acceptable load could be moved through a prescribed lift distance. This type of performance test did not provide a means of determining the strength capability at different stages along the trajectory of the lifting motion. This is important since strength is likely to be altered by the changing postures used during the motion.

The effect of the speed of motion on lifting performance is not well documented in the literature. Pytel and Kamon (1981) reported that $94.1 \%$ of the variation in psychophysically measured lifting capability could be accounted for by dynamic lifting strength measured at $0.73 \mathrm{~m} \mathrm{~s}^{-1}$ and the gender of the subject. They also reported that the magnitude of the maximum acceptable weight was $22 \%$ of the maximum dynamic lift. The intermediate postures and strength values were not recorded. Also the subjects were instructed to start the motion with a jerk, which could be difficult to control, could be unsafe, and also would tend to artificially inflate the peak strength values due to the inertial effects.

Smith et al. (1985) have reported trunk flexion/extension and trunk rotation strengths of 125 normal subjects measured by a modified Cybex machine. These experiments excluded the contributions from arms and shoulder since the exertions were against a padded bar on the chest or back. Therefore the findings are not necessarily relevant to occupational lifting situations where the arm-shoulder-trunk complex is involved. Further, the Cybex device assumed one center of motion $\left(\mathrm{L}_{5} / \mathrm{S} 1\right)$, whereas in industrial activity angular motion occurs at several levels in the spine while providing a linear displacement of the hands.

The first systematic comparative investigation of static and isokinetic strengths at three different speeds 
was reported by Kumar and Chaffin (1985). They found significant differences between static and dynamic strengths $(p<0.01)$ in back and arm lift modes $(p<0.01)$ among young men and women. Kishimo et al. (1985) have recently reported isometric and isokinetic lifting strengths from the floor to standing knuckle height with normal subjects and low-back patients at three speeds using a protype device manufactured by Lumex Corp. The authors did not describe the testing mechanism or specifications of the device. They found, like Kumar and Chaffin (1985), a decrement in strength with increasing lift speeds. Also a lower strength capability of females compared to males was described, similar to the findings of Kumar and Chaffin (1985). Contrary to the findings of Chaffin et al. (1979), they reported no significant difference between the leg and torso static strengths among their normal population. They did not investigate arm lift strengths. In a number of industries, arm lift activities are common occurrences, such as when lifting an object from or to a shoulder high shelf from a table. Furthermore, their study did not randomise the experimental trials. It is also not clear whether the isokinetic testing was done with leg lift or torso lift techniques.

In light of the above considerations, two objectives were defined for this study.

(1) To develop and evaluate a dynamic strength tester with linear velocity control.

(2) To statistically compare arm and back dynamic lifting strengths, as measured at different controlled linear velocities, with static strengths.

\section{METHODS}

To meet the first objcctive a spccial strength tester was designed to allow a repeatable and controllable isokinetic displacement in the lifting motion to occur, in addition to providing a means to perform a static mode test in any position. Using this equipment, referred to as the 'Dynamic Strength Tester' (DST), subjects of both sexes were tested for their static and dynamic strengths (at three speeds) of their back and arm lifting capabilities.

The DST device was developed and fabricated in 1983-84, when the study was conducted at The University of Michigan Centre for Ergonomics, while the first author was on a visiting appointment.

\section{DST and isometric devices, and operating methods}

The experimental instrumentation consisted of the dynamic strength tester (DST), an HP-1000 minicomputer, and an analog-to-digital (A/D) converter. The HP-1000 was used to control the experiment and acquire data from the DST via the A/D converter. The data were also stored on the HP-1000 for later analysis.

Dynamic strength tester. The dynamic strength tester was designed for performing two handed vertical, sagittally symmetrical lifts. It provided a constant speed along a fixed path motion regardless of force applied to the handles. This speed could be adjusted by a velocity controller. The constant velocity was achieved by coupling the handle guide-bar through a cable and one-way clutch to a shaft rotating at a fixed pre-set speed. The clutch uncoupled the mechanical resistance of the motor driven system until the threshold speed was reached. This allowed a resistance free vertical movement of the handiebar below the preset speed. When the speed threshold was reached the clutch engaged the constant speed shaft and controlled the speed with a very high resistance. The strength tester consisted of three components:

(1) Framework

(2) Electromechanical drive

(3) Measuring system.

(1) Framework. The framework (Fig. 1) consisted of a platform $100 \times 100 \mathrm{~cm}$ raised by $35 \mathrm{~cm}$. Two $200 \mathrm{~cm}$ high vertical guide posts were affixed to the sides of the platform toward one end. The upper ends of these vertical guide posts were braced by a crossbar. The sides of these vertical guide posts had their outer edges flared into $1 \mathrm{~cm}$ high flanges. These flanges provided a channel to guide the wheels of the moving handle bar through the vertical lift path.

(2) Electromechanical drive. The electromechanical drive (Fig. 2) consisted of an electronic speed control, a $0.25 \mathrm{HP}$ d.c. motor (GE Model 5 BCD 56 CB 173) and a mechanical drive. The motor mounted on a worm gear was connected by a timing belt and a pulley system to a central rotating shaft. A cable drive drum was mounted on the constant speed drive shaft coupled through a pair of internal one-way sprague clutches (Fig. 2). A reduction in drive vibration was achieved by attaching a flywheel on the free end of the central drive shaft. A multistrand cable was wound around the cable drum at each end, one part of which ran over a pulley under the crossbar brace. The two ends of the cable were attached to a handlebar anchor to form a pair of drive loops linking the cable drum to

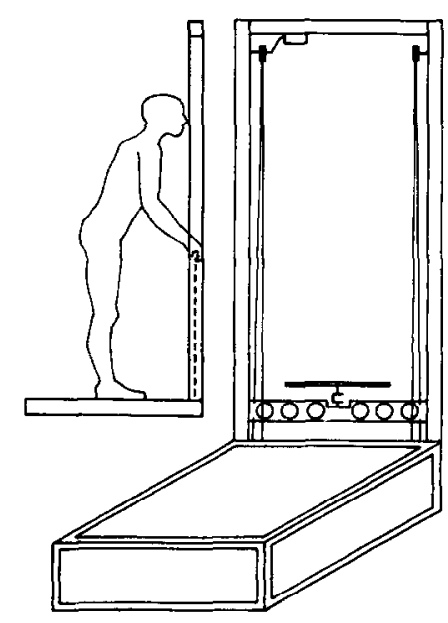

Fig. 1. Dynamic strength tester. 


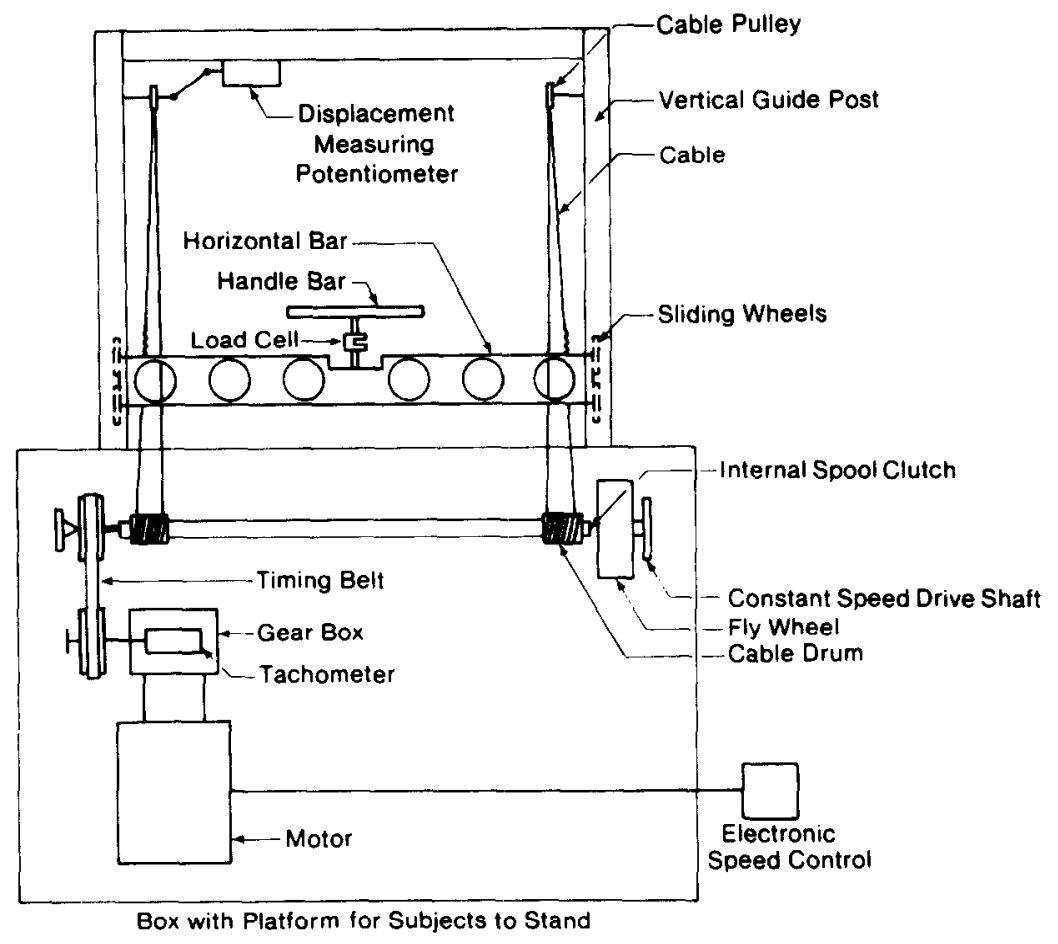

Fig. 2. Assembly of components of dynamic strength tester.

the handlebar. Mounted on the anchor was a handlebar measuring $56 \mathrm{~cm}$ long with $3.2 \mathrm{~cm}$ diameter attached through a load cell (Fig. 2). When a lifting force was applied on the handlebar it rose along the guided path at a constant preset speed. An SCR electronic speed control was used to adjust and set the speed at which the drum could rotate. The dynamic strength tester permitted a controlled 0-130 cm per second displacement of the handlebar by adjusting the speed of the motor.

(3) Measuring system. A displacement measuring potentiometer was mounted on the guidepost crossbar. This potentiometer was coupled with one cable pulley to measure the movement of the handlebar. The velocity of the handlebar was measured by a tachometer coupled by a belt to the gearbox output. The tachometer signal was the input for the SCR feedback speed control. A load cell (Interface Model SM-500-500 lb) with a natural frequency of $1.5 \mathrm{KHz}$ was inserted between the handlebar and the anchor. The output of the load cell was fed to a force monitor (ST-1, Prototype Design \& Fabrication Company) (Fig. 2).
Calibration. The speed of the motor at various control settings was calibrated manually. A maximal force of $2000 \mathrm{~N}$ was applied on the handlebar and excursion time was noted between measured and marked distances. For calibrating the handlebar displacement, it was moved through known distances of $0.5,1.0$ and $1.5 \mathrm{~m}$, and the reading of the potentiometer was taken. Static loads of 222.5, 445, 667.5 and $890 \mathrm{~N}$ were then applied to the load cell and readings taken. Each part of the calibration process was repeated ten times to ensure reliability. Errors of less than 2, 1 and $1 \%$ for each test speed were recorded.

Subjects. The experimental population consisted of ten normal young adult males and ten normal young adult females. All subjects were in good health with no history of low-back insufficiency or any other musculoskeletal problems. Anthropometric data are listed in Table 1.

\section{Experimental procedure}

All subjects were strength tested for arm and back lifting capability under the following four speed

Table 1. Anthropometric variables of the experimental population

\begin{tabular}{lrrrcccc}
\hline Gender & $\begin{array}{c}\text { Age } \\
(\mathrm{Yr})\end{array}$ & $\begin{array}{c}\text { Weight } \\
(\mathrm{kg})\end{array}$ & $\begin{array}{c}\text { Height } \\
(\mathrm{cm})\end{array}$ & $\begin{array}{c}\text { Knuckle } \\
\text { ht }(\mathrm{cm})\end{array}$ & $\begin{array}{c}\text { Shoulder } \\
\text { ht }(\mathrm{cm})\end{array}$ & $\begin{array}{c}\text { Reach } \\
(\mathrm{cm})\end{array}$ \\
\hline $\mathrm{M}$ & $\bar{X}$ & 26.6 & 76.5 & 180.8 & 82.1 & 147.0 & 61.1 \\
& $\mathrm{SD}$ & 4.5 & 9.9 & 7.24 & 5.76 & 5.5 & 3.8 \\
$\mathrm{~F}$ & $\bar{X}$ & 24.3 & 58.8 & 160.6 & 75.0 & 135.0 & 57.0 \\
& $\mathrm{SD}$ & 4.4 & 4.8 & 15.6 & 2.1 & 5.25 & 3.4
\end{tabular}


conditions:

(i) Static lift $\left(0 \mathrm{~cm} \mathrm{~s}^{-1}\right)$

(ii) Slow speed lift $\left(20 \mathrm{~cm} \mathrm{~s}^{-1}\right)$

(iii) Medium speed lift $\left(60 \mathrm{~cm} \mathrm{~s}^{-1}\right)$

(iv) Fast speed lift $\left(100 \mathrm{~cm} \mathrm{~s}^{-1}\right)$.

The combination of four speeds and two types of lift resulted in eight tasks. All dynamic back lifts were initiated in a stooped posture (straight knees and bent backs) with handlebar $5 \mathrm{~cm}$ above the ground (see Fig. 3a). The back lifts were terminated at the respective knuckle heights of each subject. The static lift was performed with the handles at the initial height of the dynamic back lift. The dynamic arm lifts (Fig. 3b) were initiated at each individual's knuckle height in an upright posture, and terminated at their shoulder heights. For static arm lifts the handlebar was fixed at each individual's knuckle height while maintaining an upright posture. For all tasks the handlebar was held with pronated hands. During the static strength tests the subjects were instructed to slowly apply force to the handlebar bringing it to their maximal level and maintaining it for a five second period, as specified in Chaffin (1975). For dynamic strength tests the instruction was to apply a force smoothly bringing it to their maximal strength capability within the first five centimeter of displacement of the handlebar motion. The dynamic lifts, depending on the speed selected, took a mean time of $0.8-4.0 \mathrm{~s}$ for the back lifts, and $0.7-3.2 \mathrm{~s}$ for the arm lifts.

Each subject upon arrival in the laboratory was weighed and measured. The subjects were asked to stand on the DST at a distance from the handlebar a)

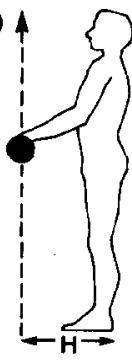

Start

b)

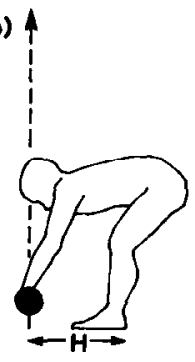

Start

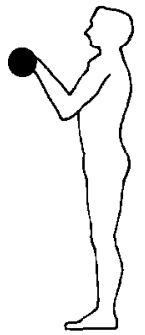

Finish

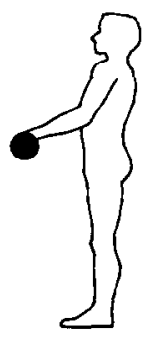

Finish
Fig. 3. Initial and final postural positions for (a) arm lift and (b) back lift most comfortable to them for the activities they had to perform. Once the feet position was chosen it was marked so that it could be maintained for all subsequent tests. The optimal horizontal distances chosen for the ankles from the handlebars by the different volunteers were different among males as well as females. The mean distances for male and females were $37.6 \mathrm{~cm}$ (S.D. 3.08 ), and $38.05 \mathrm{~cm}$ (S.D. 5.01) respectively.

The sequence of the eight test conditions was randomized. Each test condition was repeated three times and the mean of these three trials represented the mean of the statistical cell. Between the trials the subjects were given a rest of at least $2 \mathrm{~min}$.

\section{Data acquisition}

The data acquisition was managed by developing a customized software package which received data from all channels at $50 \mathrm{~Hz}$ and stored them on a hard disc. The HP 1000 computer was used as a controller with an HP 7905 disc drive and hard disc. A modular program consisting of four segments was written. The first segment was an initialization module responsible for the file creation and accepting subject an experimental information. The second segment set-up and ran the data collection program, finally writing the data generated to the files on the hard disk. The third and fourth segments displayed the collected data on the CRT for instant check of artifacts in the data and/or instrument failure.

\section{Data analysis}

Special software was written to extract data from all recorded channels at the commencement and conclusion of the eight prescribed tasks and at ten equal time intervals between. The data extracted for the static lifts were for each half a second of exertion. The duration of the dynamic lifts were variable, due to the three different speeds used in the study. Also different linear distances were travelled by the handlebar depending on lift type and an individual's lifting technique. Also, for these tasks, the initial and final heights of the activities were determined based on the anthropometry of the subject. The data at these points were taken as the initial and final readings. The intervening segment was divided into ten equal time intervals and the data pertaining to each interval point extracted. Since the DST permitted a constant velocity, the time intervals were considered to represent equal distance intervals. Thus the interval points represented identical postures for dynamic tasks with different velocity within any given lift type. For static lifts, since the postures were frozen, the interval points represented the time interval only during the activity.

The resulting interval point strength values of all trials, in addition to the entire records, were transferred from the hard disc to a magnetic tape, and then transferred to a main frame computer for statistical analysis. All strength data were subjected to analysis of variance and post-hoc comparison (Duncan-Newman- 
Keuls). The peak dynamic strength values of different velocities and lift types were regressed against their corresponding peak static strength.

\section{RESULTS}

The peak and average strength values for both static conditions and peak strength values for all dynamic conditions of all subjects were extracted from the computer record and are shown in Figs 4 and 5. The peak static strengths were invariably significantly higher than the dynamic strengths $(p<0.01)$. The peak dynamic strength decreased with increasing speed of lift (Figs 4 and 5) and occurred progressively at higher vertical displacement and later during the lifting cycle, for both back as well as arm lifts among both sexes (Table 2).

The peak strengths of females were significantly lower than those of males ranging between $56-73 \%$ for corresponding activities $(p<0.01)$. The precise percentages are shown in Table 3.

Figures 6-11 show the magnitude of the force generated by the experimental population at each of the ten equal interval points of the tests. The strength values for females were significantly lower in corresponding tests, ranging between $51-63 \%$ of the male population. The static strength after reaching its peak stayed high throughout the five second test interval. Dynamic strengths, on the other hand, gradually reached the peak with the time of the occurrence of the peak shifting a way from the start with increasing speed of the activity. Subsequent to the occurrence of the peak, the strength values significantly declined towards the end of the range of motion.

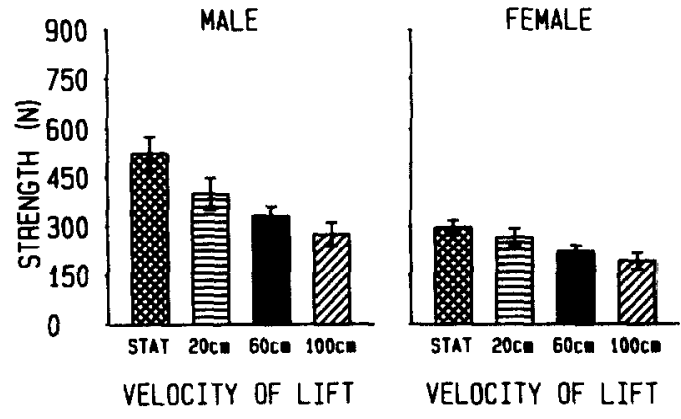

Fig. 4. Comparison of static and dynamic arm strength

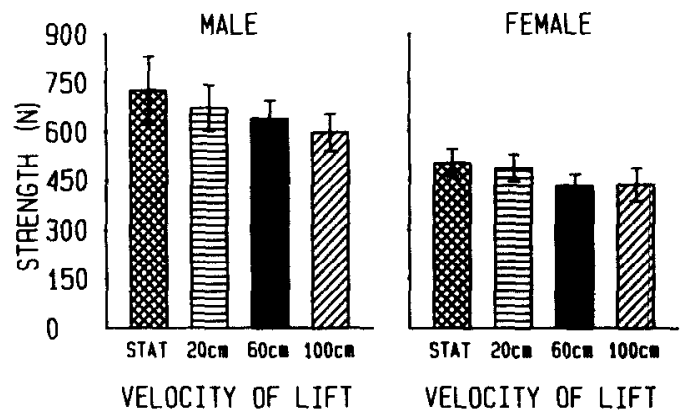

Fig. 5. Comparison of static and dynamic back strength.

The analysis of variance revealed that there were statistically significant differences between the strength values obtained during the back lifts as well as the arm lifts. These differences were due to the speed of motion, gender of subjects and speed and gender interaction.

Table 2. Mean peak dynamic strengths, their corresponding vertical hand location, activity duration and the percent of the activity

\begin{tabular}{|c|c|c|c|c|c|c|}
\hline & & & tion at wh & peak strer & occured & \\
\hline & & Tasks & $\begin{array}{c}\text { Mean } \\
\text { peak str. } \\
(\mathrm{N})\end{array}$ & $\begin{array}{c}\text { Mean } \\
\text { vertical } \\
\text { location } \\
(\mathrm{cm})\end{array}$ & $\begin{array}{c}\text { Mean } \\
\text { activity } \\
\text { duration } \\
\text { (s) }\end{array}$ & $\begin{array}{l}\text { of peak } \\
\text { occurence } \\
\text { ( } \% \text { activity } \\
\text { duration) }\end{array}$ \\
\hline & & stat. & 726 & 5.0 & 4.5 & 45 \\
\hline & Back & slow & 672 & 19.3 & 4.0 & 18 \\
\hline & & md & 639 & 33.9 & 1.3 & 44 \\
\hline & & fast & 597 & 42.4 & 0.8 & 51 \\
\hline & & stat. & 521 & 82.7 & 4.5 & 58 \\
\hline & Arm & slow & 399 & 95.1 & 3.2 & 17 \\
\hline & & md & 332 & 116.1 & 0.9 & 49 \\
\hline & & fast & 275 & 114.0 & 0.7 & 49 \\
\hline & & stat. & 503 & 5.0 & 4.5 & 41 \\
\hline & Back & slow & 487 & 15.0 & 4.2 & 19 \\
\hline & & md & 432 & 35.6 & 1.7 & 48 \\
\hline & & fast & 436 & 42.2 & 1.4 & 63 \\
\hline & & stat. & 296 & 76.2 & 4.5 & 60 \\
\hline & Arm & slow & 266 & 89.1 & 3.4 & 17 \\
\hline & & md & 221 & 95.3 & 1.4 & 34 \\
\hline & & fast & 192 & 103.7 & 1.2 & 53 \\
\hline
\end{tabular}


Table 3. Peak strength of females as percentage of males strength

\begin{tabular}{lcccc}
\hline & Static & Slow & Medium & Fast \\
\hline Back & 69 & 72 & 67 & 73 \\
Arm & 56 & 66 & 66 & 69 \\
\hline
\end{tabular}

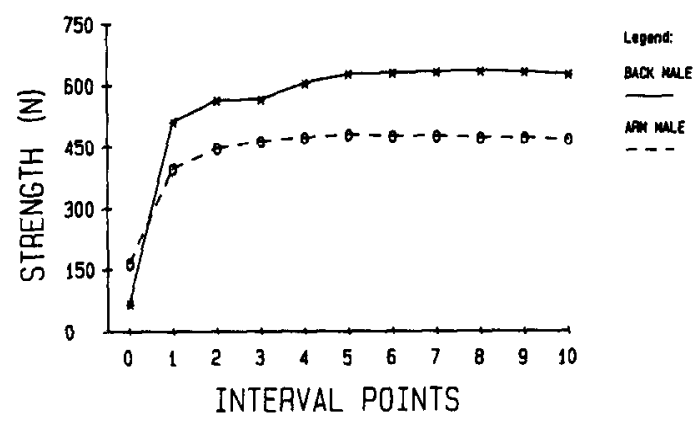

Fig. 6. Interval point isometric arm and back strengths of males.

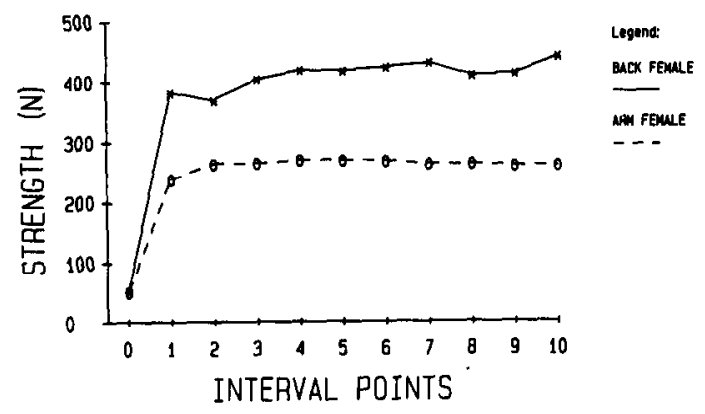

Fig. 7. Interval point isometric arm and back strenghs of females.

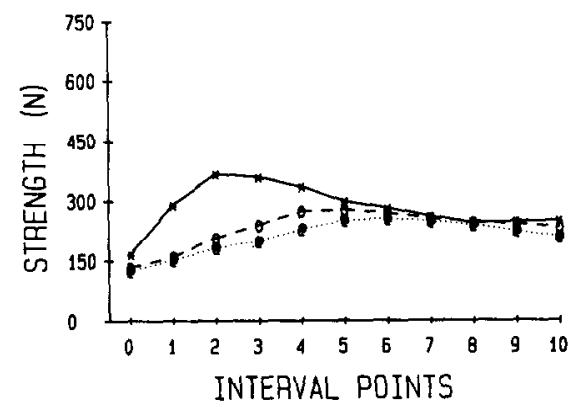

Fig. 8. Interval point isokinetic arm strength of males.

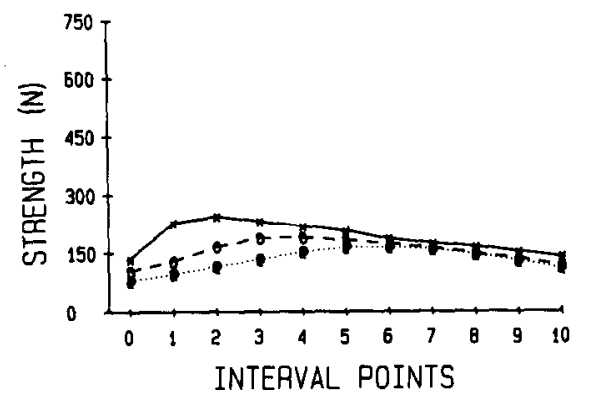

Fig. 9. Interval point isokinetic arm strength of females.

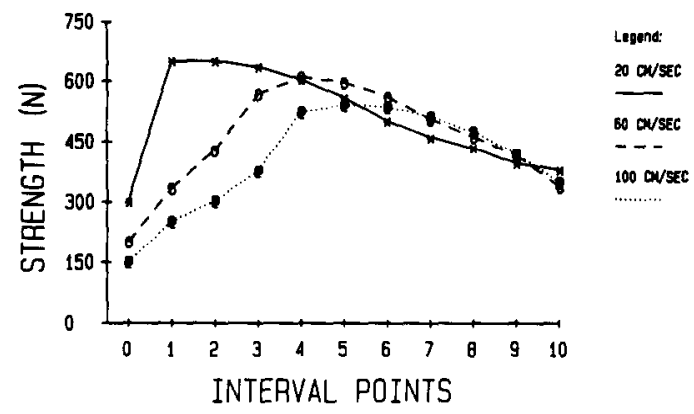

Fig. 10. Interval point isokinetic back strength of males.

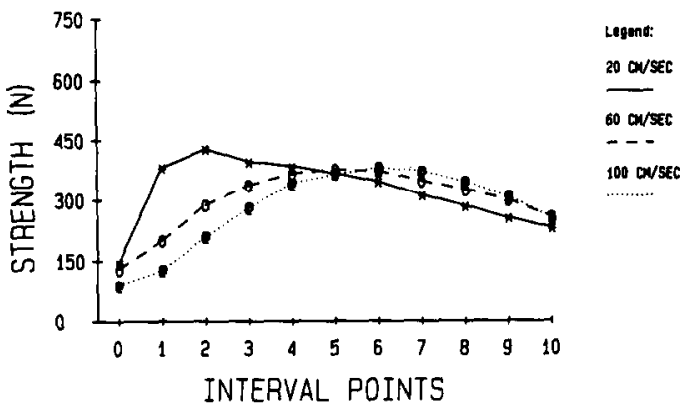

Fig. 11. Interval point isokinetic back strength of females.

Table 4. Summary table of analysis of variance showing the factors affecting the strength

\begin{tabular}{|c|c|c|c|c|c|}
\hline \multirow[b]{2}{*}{ Source } & \multirow[b]{2}{*}{ DF } & \multicolumn{2}{|c|}{$\underset{F}{\text { Arm lift }}$} & \multicolumn{2}{|c|}{$\begin{array}{l}\text { Back lift } \\
F\end{array}$} \\
\hline & & ratio & $p<$ & ratio & $p<$ \\
\hline Speed & 3 & 36.06 & 0.00 & 3.73 & 0.01 \\
\hline Gender & 1 & 77.64 & 0.00 & 33.79 & 0.00 \\
\hline Speed-gen. & 3 & 5.02 & 0.00 & 0.24 & 0.86 \\
\hline Percentile & 10 & 53.57 & 0.00 & 86.26 & 0.00 \\
\hline $\begin{array}{l}\text { Percentile } \\
\text { speed }\end{array}$ & 30 & 9.73 & 0.00 & 12.23 & 0.00 \\
\hline $\begin{array}{l}\text { Percentile } \\
\text { gender }\end{array}$ & 10 & 4.34 & 0.00 & 3.00 & 0.02 \\
\hline $\begin{array}{l}\text { Percentile } \\
\text { speed-gen. }\end{array}$ & 30 & 0.52 & 0.83 & 0.99 & 0.44 \\
\hline
\end{tabular}

The interval point values also had significant differences due to the speed of activity, gender of subject and their interaction (Table 4). The speed and gender interaction did not have a significant effect on back lift strength. Similarly speed, gender and interval point interaction was insignificant for both back and arm lifts. Interval point and speed interaction, and interval point and gender interaction were statistically significant at $p<0.01$ level. The post-hoc analysis for interaction between interval point and speed showed a tendency for clustering of maximum strength values in the central motion region. The initial and final point values were significantly different from the mid zone values. Among the slow speed $\left(20 \mathrm{~cm} \mathrm{~s}^{-1}\right)$ trials, the unique interval point strength values were limited to either initial or initial and final point values (Fig. 3a 
and b). Medium and fast speed activities had this effect even more pronounced. This effect was more evident in the back lifts as compared to the arm lifts.

Simple regressions were obtained between the peak dynamic strengths at the three speeds of back lift. regardless of posture and time of occurrence, and the peak static strength for both males and females. The regression equations are described below and the plots are shown in Figs 12-17.

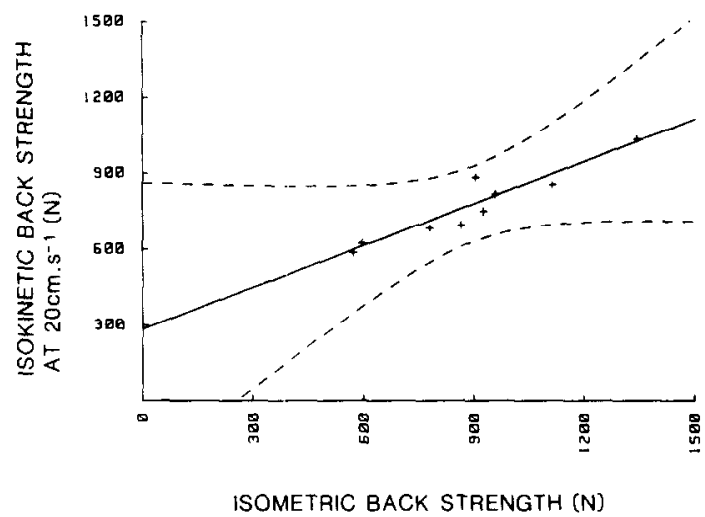

Fig. 12. Bivariate regression plot of isokinetic back strength at $20 \mathrm{~cm} \mathrm{~s}^{-1} \mathrm{vs}$ isometric back strength among males.

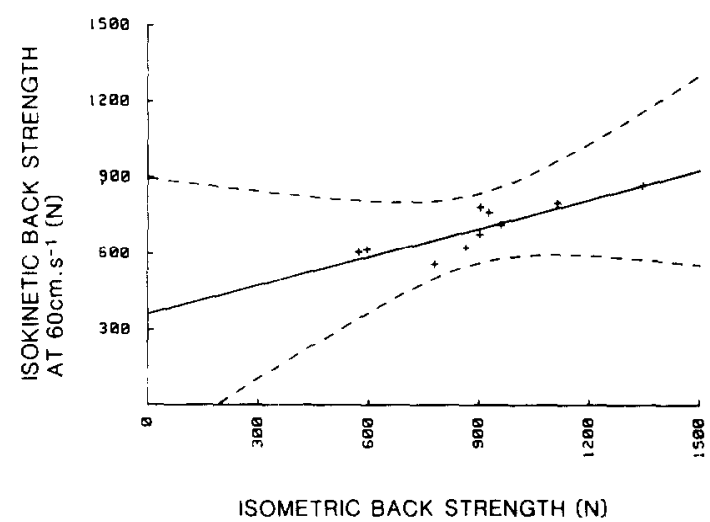

Fig. 13. Bivariate regression plot of isokinetic back strength of $60 \mathrm{~cm} \mathrm{~s}^{-1}$ vs isometric back strength among males.

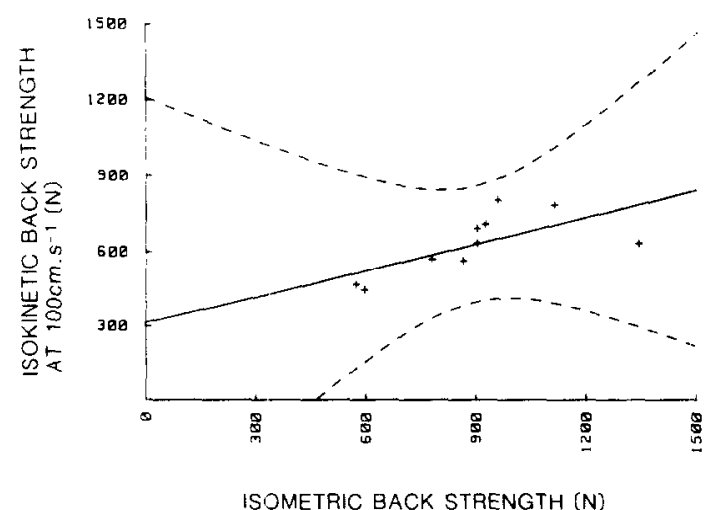

Fig. 14. Bivariatc regression plot of isokinetic back strength at $100 \mathrm{~cm} \mathrm{~s}^{-1}$ vs isometric back strength among males.

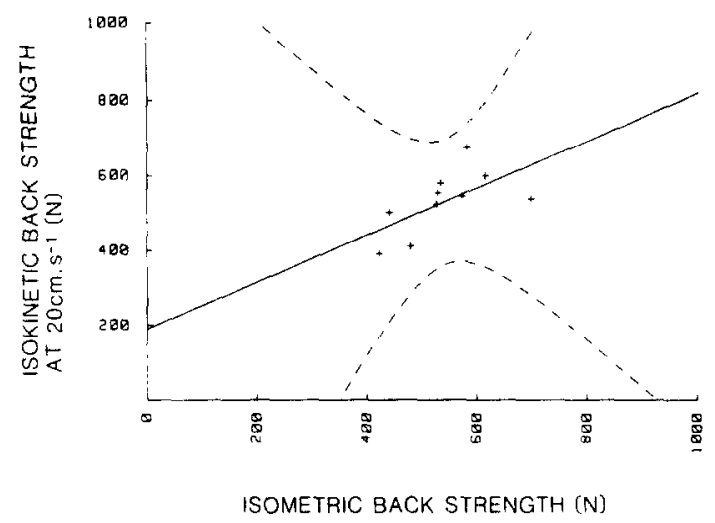

Fig. 15. Bivariate regression plot of isokinetic back strength at $20 \mathrm{~cm} \mathrm{~s}^{-1}$ vs isometric back strength among females.

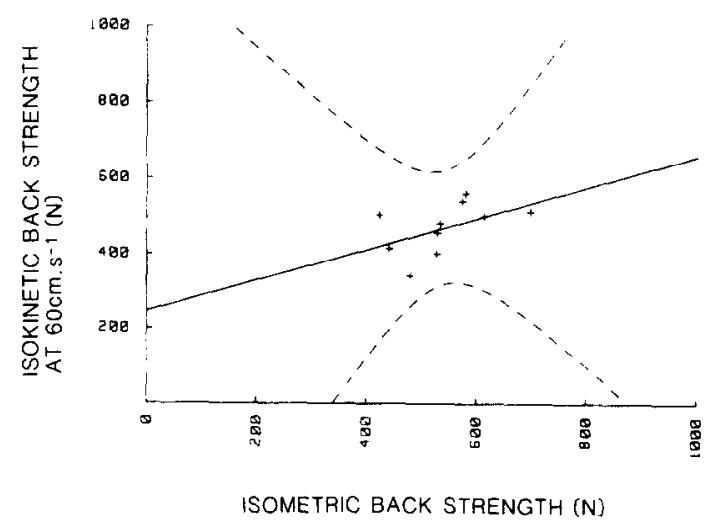

Fig. 16. Bivariate regression plot of isokinetic back strength at $60 \mathrm{~cm} \mathrm{~s}^{-1}$ vs isometric back strength among females.

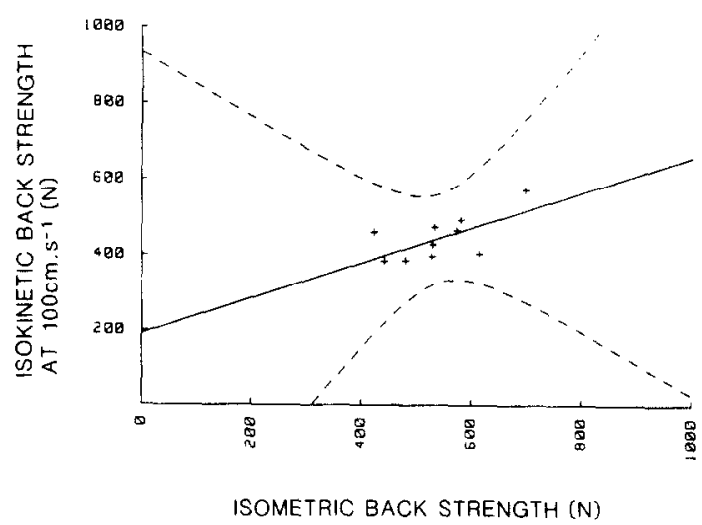

Fig. 17. Bivariate regression plot of isokinetic back strength at $100 \mathrm{~cm} \mathrm{~s}^{-1}$ vs isometric back strength among females.

Males:

$\mathrm{DS}$ (Slow) $=0.55 \mathrm{SS}+63.04 ; r=0.91, p<0.01$

$\mathrm{DS}$ (Med) $=0.37 \mathrm{SS}+80.57 ; r=0.85, p<0.01$

$\mathrm{DS}$ (Fast) $=0.35 \mathrm{SS}+70.14 ; r=0.67, p<0.05$

Fcmales:

$\mathrm{DS}$ (Slow) $=0.62 \mathrm{SS}+43.03 ; r=0.62, p<0.05$

DS $($ Med) $=0.40 \mathrm{SS}+55.49 ; r=0.59, p<0.05$

DS (Fast) $=0.47 \mathrm{SS}+42.65 ; r=0.65 ; p<0.05$ 


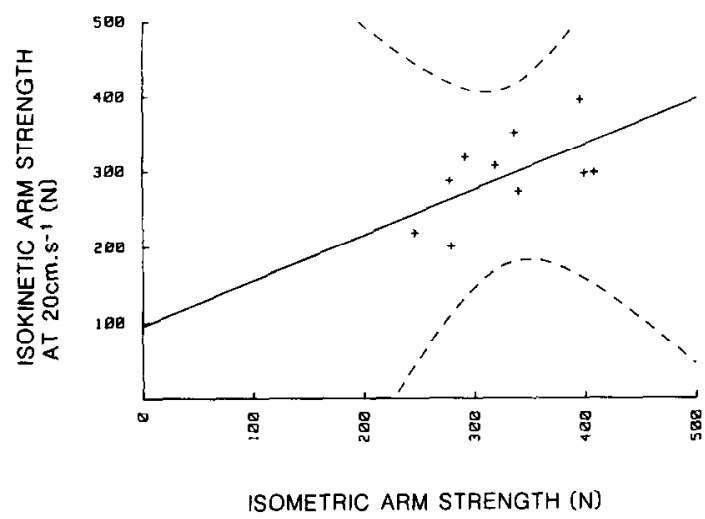

Fig. 18. Bivariate regression plot of isokinetic arm strength at $20 \mathrm{~cm} \mathrm{~s}^{-1}$ vs isometric arm strength among females.

Simple bivariate regression for arm lifts were insignificant for subjects of both sexes, except for the slow speed lifts by females. The regression equation and the plot (Fig. 18) follows:

$$
\mathrm{DS}(\mathrm{Slow})=0.61 \mathrm{SS}+21.23 ; r=0.60, p<0.05 \text {. }
$$

\section{DISCUSSION}

Objections to the suitability of 'strength' as a task design criterion for controlling back injuries in the work place have been raised (Ayoub, 1982). The objections were based on considerations that strength as appearing in the current literature, is most often a measure of two handed static effort, which may not be a good simulation of most industrial manual work. It is acknowledged by most authorities, however, that static tests are relatively safe, repeatable, simple to administer, and correlate with injury risk potential. Interest in dynamic strength measurement is a recent phenomenon. Pytel and Kamon (1981) used a commercially available 'Mini-Gym' (Model 101) and modified it for isokinetic conditions. They did not report the accuracy of the system. Others have employed the Cybex II with various degrees of modification (Langarana and Lee, 1984; Marras, King and Joynt, 1984; Smith, Mayer, Gatchel and Becker, 1985; and others). The Cybex is designed to measure torque at one joint. Most authors have not attempted to measure the change in lever arm due to motion of the chest pad. As such, the force output of the trunk muscles cannot be easily used to predict whole-body lifting capability.

Lifting and manual materials handling activities often involve angular motion at several joints involving many links resulting in a near linear type displacement of the hands. It is essential to simulate this motion in strength testing for the results to be relevant as an improved design criterion for manual materials handling activities, or to be used more effectively in evaluating a persons ability to perform such tasks in industry. While motion trajectory of the tasks studied remains constrained by design, but is dynamic and appears to provide significant improvement over the static methods. It must also be emphasised that the results reported here are more relevant to tasks with similar motion trajectory.

Kishino and Mayer et al. (1985) recognising the limitations used an isokinetic lifting strength tester produced by Lumex Corp. Unfortunately, the accuracy of the equipment was not specified by the authors, despite the fact it was a prototype design. Also, they did not define the dynamic lifting task well. It is unclear whether their subjects were asked to perform a 'leg lift' or a 'torso lift', and an arm lift was not investigated.

In the current study the subjects were specifically instructed to perform a stoop lift and arm lift. Prior to each session the subjects were trained for these tasks. The speeds and the tasks were randomised contrary to the Kishino study. In the latter, a learning or fatigue effect could have influenced the results as they used a progressively increasing speed, varying at 45,75 and $90 \mathrm{~cm}$ per second for isokinetic testing. The present study used 20,60 and $100 \mathrm{~cm}$ per second speed for the handlebar displacement.

The DST device designed for this project was accurate within $\pm 2 \%$ for the speed of motion and $\pm 1 \%$ for force and displacement measurements. The results obtained were consistently repeatable within these limits. A continuous $(50 \mathrm{~Hz}$ sampling rate) measurement of these variables, along with similar continuous recording of the posture during all activities enabled the authors to evaluate the strength results at 10 equal interval points over the total displacement of the hands. By such a selection any two consecutive interval points were never more than $10 \mathrm{~cm}$ apart. A linear excursion of the handlebar by the interval distance changed the overall posture by a small amount. Since the activities chosen were isokinetic the transition from one posture to the next was expected to be smooth. Given these conditions it was thought that the strength readings obtained from the 10 interval points were valid measurements from which conclusions could be based with confidence.

The results obtained from this experiment demonstrate that peak static and dynamic lifting strength capabilities were significantly different from each other over the lifting range. The static strengths were significantly higher than the dynamic strengths. Pytel and Kamon (1981) however, reported a $10 \%$ increase among men and $21 \%$ increase among women in a dynamic back lifting with a speed of $73 \mathrm{~cm} \mathrm{~s}^{-1}$ over corresponding static strength values. At $97 \mathrm{~cm} \mathrm{~s}^{-1}$ speed of dynamic back lift though, there was a $31 \%$ decrease in men and $19 \%$ decrease in women. In arm lifts an increase of $12.5 \%$ in men was reported at a speed of $73 \mathrm{~cm} \mathrm{~s}^{-1}$. However, it declined by 19 and $28 \%$ in males and females respectively at the speed of $97 \mathrm{~cm} \mathrm{~s}^{-1}$. The increased strength in dynamic lifting performed at a speed of $73 \mathrm{~cm} \mathrm{~s}^{-1}$ is thought to have occurred due to the lifting instruction given to subjects to lift as fast as they could resulting in a jerk, possibly 
inflating the values. Smith et al. (1985) have also reported a $3 \%$ increase in slow dynamic trunk extensor activities over the static exertions. However with increasing speed they also encountered a significant decline in the trunk strength. The data of Smith $e t$ al. (1985) is not considered directly comparable to this study, however, as they isolated trunk motions in their study, whereas the current study has investigated the arm, shoulder and trunk complex in a lifting activity. Furthermore, Smith et al. (1985) reported torque values without the details of lever arm length, thus preventing deduction of lifting force values. Nevertheless the extent of relative decline in peak strength due to the increase in the speed of activity was consistent with the findings of this study.

The recent study reported by Kishino and Mayer $e t$ al. (1985) is more similar to this study. However, for the reasons stated above, a direct comparison cannot be derived. except for the static torso lift. For the latter, the strengths of females were similar to this study (Kishino et al., $538 \mathrm{~N}$; this study, $503 \mathrm{~N}$ ), but those of males were significantly different (Kishino et al. $918 \mathrm{~N}$; this study $726 \mathrm{~N}$ ).

The difference between the peak static strength and peak dynamic strength at $20 \mathrm{~cm} \mathrm{~s}^{-1}$ was smaller. The peak strength at the speed of $60 \mathrm{~cm} \mathrm{~s}^{-1}$ was considerably less, and significantly different from that of the static peak strengths in both studies. The percentage decline standardised against the peak static strengths for the respective lift types are shown in Table 5 .

As lifting speed is increased it could cause a greater hazard to a person than is now indicated by static strength values. Static strengths measured in an optimum posture is an indicator of maximal capability. Due to change in posture strength capability is signifcantly altered. In the current study the static arm lift strength was $29 \%$ lower than the back strength. A similar reduction in arm lift strength was also reported by Yates et al. (1980), Pytel and Kamon (1981) and Kroemer (1983). Using a psychophysical technique Ayoub (1978) and Snook (1978) determined maximum acceptable weight to be lifted and found that the magnitude declined as the height was increased. Comparing the dynamic back lift with corresponding dynamic arm lift a decrement ranging from 37 to $54 \%$ was found in males and $39-56 \%$ in females. It is suggested therefore, that task design should be more appropriately based on the lowest strength for the appropriate range of postures required on a job, rather

Table 5. The percentage decline in dynamic strength standardised against peak static strength

\begin{tabular}{llrcc}
\hline & & Slow $^{-1}$ & Medium $^{-1}$ & Fast $^{-1}$ \\
\hline \multirow{2}{*}{ Arm lift } & Males & 23.4 & 36.3 & 74.3 \\
& Females & 9.3 & 29.4 & 39.1 \\
Back lift & Males & 7.5 & 12.0 & 17.7 \\
& Females & 3.4 & 15.2 & 14.3 \\
\hline
\end{tabular}

than the best possible performance in an optimum posture. In other words, strength tests should be established only after a biomechanical evaluation of the job has determined the postures wherein the greatest relative strength is required.

Progressively higher vertical locations of peak strength occur with increasing speed of motion (Table 2), and different back and arm lift strengths ( $p$ $<0.001$ ) suggest that materials that are lifted quickly in a job should be raised to a suitable level.

The dynamic strength was variable through the range of postures. It is believed that such a conclusion, in view of the instructions given to the subjects to exert their maximum throughout the range, depicts the true strength variation when lifting in a dynamic mode. Therefore, the range of motion involved in a given exertion is considered an essential variable to be considered in specifying the difficulty of a manual lifting task.

The peak dynamic strength for the back lift was significantly correlated with the static peak strength. Though these peak strengths can be predicted, as stated earlier, they must not be considered the best single selection criteria. Improved selection tests in the future will need to be based on tests that accurately reflect the dynamic requirements of a job. It is believed that this study begins to establish an understanding of such dynamic tests and how they can be interpreted.

In conclusion the two objectives of the study were met. A reliable dynamic strength tester with a linear velocity control was developed. The static and dynamic strength at three linear velocities were statistically compared for arm and back lifts. The resulting relationships are discussed.

Acknowledgements-The authors wish to acknowledge help and suggestions received from Jim A. Foulke of the Center of Ergonomics of the University of Michigan, and Laurie Mendenhal, President of Prototype Design and Fabrication Company, Ann Arbor, Michigan who designed and built the Dynamic Strength Tester to prescribed specification used in this study in the fall and winter of 1983-84.

Financial support from Firestone Tire \& Rubber Co. and Marathon Foundation is also gratefully acknowledged.

\section{REFERENCES}

Ayoub, M. A. (1982) The manual lifting problem: the illusive solution. J. occup. Accidents 4, 1-23.

Ayoub, M. M., Bethea, N. J., Deivanayangam, S., Asfour, S. S. Bakken, G. M., Liles, D., Mital, A. and Sherif. M. (1978) Determination and modeling of lifting capacity. Final Report, HEW (NIOSH) Grant No. 5 R01 OH-00545-02.

Chaffin, D. B. (1975) Ergonomic guide for the assessment of human static strength. Am. ind. Hyg. Ass. J. July, 505-510. Chaffin, Don, B., Herrin, G. D. and Keyserling, W. M. (1978) Pre-employment strength testing. An updated position. J. occup. Med. 20, 403408 .

Holbrook, T. L., Grazier, K., Kelsey, J. L. and Stauffer, R. N (1984) The frequency of occurrence, impact and cost of selected musculoskeletal conditions in the United States. American Academy of Orthopaedic Surgeons. 
Keyserling, W. M., Herrin, G. D. and Chaffin, Don B. (1980) Isometric strength testing as a means of controlling medical incidents on strenuous jobs. J. occup. Med. 22, 332-336.

Kishino, N. D., Mayer, T. G., Gatchel, R. J., Parrish, M. M Anderson, C., Gustin, L. and Mooney, V. (1985) Quantification of lumbar function. Part 4: Isometric and isokinetic lifting simulation in normal subjects and lowback dysfunction patients. Spine 10, 921-927.

Kroemer, K. H. E. (1983) An isoinertial technique to assess individual lifting capability. Human Factors 25, 493-506.

Kumar, S. and Chaffin, Don B. (1985) Static and dynamic lifting strengths of young adults. Xth International Society of Biomechanics, Umea, Sweden. 15-20 June.

Langarana, N. A. and Lee, C. K. (1984) Isokinetic evaluation of trunk muscles. Spine 9, 171-175.

Marras, W. S., King, A. I. and Joynt, R. L. (1984)
Measurement of loads on the lumbar spine under isometric and isokinetic conditions. Spine 9, 176-187.

Pytel, J. L. and Kamon, E. (1981) Dynamic strength test as a predictor for maximal and acceptable lifting. Ergonomics 24, 663-672.

Smith, S. S., Mayer, T. G., Gatchel, R. J. and Becker, T. J. (1985) Quantification of lumbar function. Part I: Isometric and multispeed isokinetic trunk strength measures in sagittal and axial planes in normal subjects. Spine 10 757-764.

Snook, S. H. (1978) The design of manual handling tasks Ergonomics 21, 963-985.

Yates, J. W., Kamon, E., Rodgers, S. H. and Champney, P. C. (1980) Static lifting strength and maximal isometric voluntary contractions of back, arm and shoulder muscles. Ergonomics 23, 37-47. 